Pathologe 2016 37 (Suppl 2):S26

DOI 10.1007/s00292-016-0229-x

Online publiziert: 19 . September 2016

๑) Springer-Verlag Berlin Heidelberg 2016

\section{P. Möller}

Institut für Pathologie, Universitätsklinikum Ulm, Ulm, Deutschland

\section{Otto Haferkamp}

\subsubsection{6-05.04.2016}

Herr Prof. Dr. Otto Haferkamp, geboren am 29. Dezember 1926, ist nach sehr langer Krankheit am 05. April 2016 verstorben. Die Beerdigung fand am 19. April auf dem Ulmer Hauptfriedhof im Beisein seiner Familie und von Vertretern der Universität Ulm, ehemaligen Ordinarienkollegen und aktuellen und ehemaligen Angehörigen des Instituts für Pathologie statt.

Vor seinem Ruf nach Ulm war Prof. O. Haferkamp seit 1951 am Pathologischen Institut der Universität Bonn tätig, zunächst als Volontärassistent, $\mathrm{ab}$ 1954 als wissenschaftlicher Assistent. Mit einer Arbeit „Über die Neurome“ habilitierte er sich 1960. Im gleichen Jahr wurde er zum Oberassistenten ernannt. 1965 wurde er außerplanmäßiger Professor und 1966 Abteilungsvorsteher und Professor an diesem Institut. In dieses Jahr fällt ein Forschungsaufenthalt in den USA (01.10. - 31.12.1966), den er als Gastprofessor an der State University of New York verbrachte. Seine in dieser Zeit erschienenen Arbeiten zur experimentellen Immunpathologie, einem Gebiet, das ihn seit 1959 interessierte, führten zu seiner Berufung nach Ulm.

Prof. Dr. O. Haferkamp war ab 1969 zusammen mit Prof. Dr. Günther Beneke Gründungsordinarius des Ulmer Pathologischen Instituts, das anfangs „Abteilungen I und II für Pathologie im Zentrum für medizinische Grundlagenforschung der Universität Ulm“ hieß. Nach dem frühen Tod von Prof. Dr. G. Beneke im Jahr 1974 leitete Prof. Haferkamp das Institut allein bis zu seiner Emeritierung zum Jahr 1995.

Prof. Dr. O. Haferkamp war während seiner gesamten Amtszeit bekennender Sektionssaalpathologe und betreute diagnostisch ein großes extrauniversitäres Umfeld. Er war von 1975 bis 1978 De- kan der Fakultät für Theoretische Medizin. Zwei seiner Schüler sind Ordinarien geworden: Prof. em. Dr. B. Bültmann (Tübingen) und Prof. em. Dr. C. J. Kirkpatrick (Mainz).

Prof. Dr. O. Haferkamp hinterlässt über 200 wissenschaftliche Publikationen, die sich vornehmlich mit den Themen Infektionskrankheiten, Pathologie der Entzündung und Immunpathologie beschäftigt haben. Darunter seien folgende auch aus heutiger Sicht bemerkenswerte Arbeiten paradigmatisch erwähnt:

- Heymer B, Bültmann B, Haferkamp O (1971) Toxicity of Streptcoccal mucopeptides in vivo and in vitro. J Immunol 106:858-861,

- Heymer B et al. (1973) A latex agglutination test for measuring antibodies to Streptococcal mucopepdides.

J Immunol 111:478-484,

- Heymer B et al. (1973) Migration inhibition of rat peritoneal cells induced by Streptococcal mucopeptides. Characteristics of the reaction and properties of the mucopeptide preparations. J Immunol 116:1743-1754,

- Bültmann B et al. (1983) Age dependence of paralysis induced by echovirus type 9 in infant mice. J Infect Dis 147:999-1005,

- Bültmann B et al. (1984) F-Met-LeuPhe and echo 9 virus interaction with granulocytes. Changes of cell membrane structure. Am J Pathol 116:46-55,

- Haferkamp O et al. (1993) Neurophilic migration through capillarylike micropores: influence of pulmonary passage. Clin Invest 72:30-35,

- Haferkamp O et al. (1994) Mitochondrial complex I and III mutations and neutral-lipid storage in activa- ted mononuclear macrophages and neurtophils: a case presenting with necrotizing myopathy, poikiloderma atrophicans vasculature, and xanthogranulomatous bursitis. Hum Pathol 25:419-423.

$\mathrm{Zu}$ Amtszeiten war Prof. Dr. O. Haferkamp auf den Kongressen und Herbsttagungen der Deutschen Gesellschaft für Pathologie eine durch seine schiere Körperfülle und seine rheinische Frohnatur auffallende Erscheinung, die mit geistreichen und witzigen Einlassungen das Auditorium in gehobene Stimmung zu versetzen wusste. Als Emeritus lebte er sehr zurückgezogen und auf seine kleine Familie konzentriert.

\section{Peter Möller}

Ulm

\section{Korrespondenzadresse}

\section{Prof. Dr. P. Möller}

Institut für Pathologie, Universitätsklinikum

Ulm

Albert-Einstein-Allee 23, 89070 Ulm,

Deutschland

peter.moeller@uniklinik-ulm.de 